\title{
INFLUENCE OF THE LONGITUDINAL DISPLACEMENT ON NONLINEAR PRINCIPAL PARAMETRIC RESONANCE OF THE WOODWORKING BANDSAW
}

\author{
Roberto Žigulić, Cristiano Fragassa, Ante Skoblar
}

Original scientific paper

The transverse vibrations of axially moving Timoshenko beam, as suitable mathematical models for woodworking bandsaws, are investigated. Specia attention is paid to the influence of longitudinal displacement effect, as opposed to most models which can be usually encountered in the literature. This influence is introduced through the integro-partial differential equations. The expressions for the mode shapes in the case of hybrid supports with different torsion spring stiffness on the support points are also derived. The influence of mean beam velocity and axial tension on its natural frequencies and mode shapes is also investigated. Based on the nonlinear model, the amplitudes of the steady-state response are calculated for the case of principal parametric resonance. Developed program solution was tested on a number of earlier known examples. Present theoretical considerations, with the help of the program solution, is also used to analyse an example from industrial practice.

Keywords: hybrid boundary conditions; method of multiple scales; numerical examples; principal parametric resonance; travelling Timoshenko beam

Utjecaj uzdužnog pomaka na nelinearne glavne parametarske rezonancije tračne pile

Izvorni znanstveni članak

U radu su istražene poprečne vibracije aksijalno pomične Timoshenkove grede, kao podesnog modela za matematičko modeliranje tračnih pila. Posebno je obrađen utjecaj aksijalnog pomaka koji je, za razliku od većine modela koji se susreću u literaturi, uveden preko integro-parcijalne diferencijalne jednadžbe. Također su izvedeni izrazi za forme vibriranja za slučaj hibridnih oslonaca s različitim krutostima torzijskih opruga u točkama oslonaca Ispitivan je utjecaj srednje brzine gibanja grede kao i aksijalnog naprezanja na vlastite frekvencije i oblike vibriranja. Razvijen je i nelinearni model na temelju kojega su izračunati amplitudni odzivi nelinearnih ravnomjernih vibracija za slučaj parametarske rezonancije. Izrađeno programsko rješenje testirano je na određenom broju ranije poznatih primjera. Iznijeta teorijska razmatranja, uz pomoć programskog rješenja, poslužila su i za analizu jednog od dostupnih primjera iz industrijske prakse.

Ključne riječi: glavna parametarska rezonancija; metoda višestrukih skala; mješoviti rubni uvjeti; numerički primjeri; pomična Timoshenkova greda

\section{Introduction}

The axially moving systems are nowadays applied in many areas of machinery. The class of axially moving continua encompasses such apparently diverse mechanical systems as power transmission chains, conveyor belts, bandsaw blades, aerial cableways, elevator cables, pipes containing flowing fluid etc. [3, 4].

Transverse vibrations of such systems are able to generate many disadvantageous effects. For example, the torsional oscillations of the pulleys managing the motion of the conveyor belt, might result in the small fluctuation in the axial speed of the belt [5]. The similar phenomenon is observed also in the case of bandsaws, where increased vibrations usually result in wastage of raw material, reduced tool life, cutting inaccuracies as well as poor surface quality $[6 \div 8]$. From the reason that axial speed of a beam may significantly affect the dynamic characteristics of the structure even at a low velocity, it is important to accurately predict the dynamic characteristics and stability of such structures. Therefore, investigating in this area is still of great interest today having an important engineering significance in controlling and optimizing the transverse dynamics of axially moving systems.

Many contributions in the field of axially moving continuum can be found in the relevant literature, but due to the topic of the paper, only the relevant papers connected with travelling beams will be mentioned. The first mathematical model of bandsaw vibration based on the Hamilton principle [9], enabled the calculation of three lowest natural frequencies as well as vibration modes.
In many axially moving systems, the axial transport speed has almost constant value with small periodic fluctuation which can be excitation for nonlinear vibrations. That is the reason why perturbation methods, such as method of multiple scales, matched asymptotic expansion, method of averaging etc. are nowadays useful techniques in studying the nonlinear vibrations of axially moving continuum. Wickert [10] used the asymptotic method of Krylov, Bogolyubov and Mitroolsky (KBM) to analyse the free non-linear vibrations of an axially moving, elastic, tensioned beam over the subcritical and supercritical transport speed ranges. Öz et al. [11] discussed the transition behaviour from string to beam, and for the first time employed the method of multiple scales to study dynamic stability of an axially accelerating beam with small bending stiffness. Özkaya and Pakdemirli [12] combined the method of multiple scales and the method of matched asymptotic expansions to construct non-resonant boundary layer solutions for an axially accelerating beam with small bending stiffness. They compared results with the outer solution given by Öz et al. [11].

In general, the papers deal with two main types of travelling beam excitation (external and parametric excitation) or its combination. Huang et al. [13] applied incremental harmonic balance (IHB) method to analyse three-to-one subharmonic internal resonance. Tang and all [14] investigated primary resonances as well as subharmonic and superharmonic resonances caused by weak and strong external excitations of axially moving Timoshenko beam. Ding and $\mathrm{Zu}$ [15] found periodic and chaotic responses of Euler-Bernoulli beam subjected simultaneously to two types of excitation, external 
harmonic excitation and parametric excitation from harmonic fluctuations of the moving beam speed. The periodic and chaotic behaviour showed also parametrically excited axially accelerating viscoelastic Timoshenko beam studied by Yan et al. [16].

Boundary conditions have significant influence on vibration characteristics of distributed parameter systems. In the vast majority of the related papers, boundary conditions under consideration are chosen as simple (pinned) ends $[11 \div 16]$. However there are some papers, dealing with other boundary conditions. Tang et al. [17] analyzed natural frequencies as well as vibration modes of axially moving Timoshenko beams supported by different supports (simple-simple supports, clamped-clamped (fixed-fixed) supports and simple supports with torsional springs). Chen and Yang [23] investigated non-typical boundary conditions e.g. used rotating sleeves with torsional springs. Ding et al. [18] used similar boundary conditions, obtaining supercritical equilibrium and critical speeds of travelling beam. In all of three cases, two models based on nonlinear integro-partial-differential equation [10] as well as nonlinear partial-differential equation are compared [19].

Present paper is organized as follows: Chapter 2 establishes the governing equations for the model based on nonlinear partial differential equation and model based on nonlinear integro - partial differential equation. Chapter 3 applies the Method of multiple scales (MMS) for obtaining the linear and nonlinear response of the axially moving Timoshenko beam supported on hybrid supports. Chapter 4 provides results of a few numerical examples compared with the earlier known examples as well as a new example of the bandsaw from the industrial practice. Chapter 5 gives concluding remarks.

\section{Problem definition and modelling}

In the paper uniform axially moving Timoshenko beam shown in fig. 1 with length $l$ and mass density $\rho$ is considered.

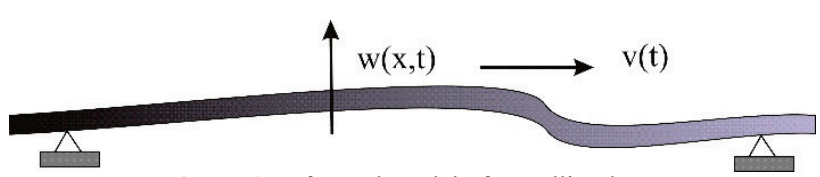

Figure 1 Deformed model of travelling beam

The beam is characterized with flexural rigidity $R=E I$ (where $E$ is Young's modulus of elasticity and $I$ is area moment of inertia of the cross - section about the neutral axis), shear rigidity $S=k G A$ (where $k$ is shear coefficient (shape factor), $G$ is beam shear modulus and $A$ is cross section area) and its axial stiffness $E A$. The axial tension of the beam is $P$ and beam travels between the two supports with the transport velocity $v(t)$. According to the Timoshenko beam theory $u(x, t)$ is longitudinal, $w(x, t)$ is transversal displacement of the beam and $\psi(x, t)$ is a slope of the cross-section.

Applying the Newton's second law in the longitudinal, transversal as well as angular direction yields:

$$
\begin{aligned}
& \rho A\left(\frac{d^{2} u}{\mathrm{~d} t^{2}}+\frac{\mathrm{d} v}{\mathrm{~d} t}\right)=\frac{\partial}{\partial x}\left(E A\left(\frac{\partial u}{\partial x}+\frac{1}{2}\left(\frac{\partial w}{\partial x}\right)^{2}\right)\right), \\
& \rho A \frac{\mathrm{d}^{2} w}{\mathrm{~d} t^{2}}=P \frac{\partial^{2} w}{\partial x^{2}}+\frac{\partial}{\partial x}\left(S\left(\frac{\partial u}{\partial x}\left(\psi-\frac{\partial w}{\partial x}\right)\right)\right)+ \\
& +\frac{\partial}{\partial x}\left(E A\left(\frac{\partial u}{\partial x}+\frac{1}{2}\left(\frac{\partial w}{\partial x}\right)^{2}\right) \frac{\partial w}{\partial x}\right), \\
& \rho I \frac{\mathrm{d}^{2} \psi}{\mathrm{d} t^{2}}=\frac{\partial}{\partial x}\left(E I \frac{\partial \psi}{\partial x}\right)-R\left(\psi-\frac{\partial w}{\partial x}\right) .
\end{aligned}
$$

In the equations of motion (1) $\div(3)$, the $\rho A$ is specific mass per unit length of the beam and $\rho I$ is its moment of inertia. Similar equations, for the Timoshenko beam without travelling effect are given in [1]. The obtained equations are not convenient for the analysis since they include many parameters. In order to facilitate the general analysis the dimensionless variables and parameters are introduced as follows:

$$
\begin{aligned}
& \hat{u}=\frac{u}{l}, \hat{w}=\frac{w}{l}, \hat{x}=\frac{x}{l}, \hat{\psi}=\frac{\psi}{l}, \hat{t}=t \sqrt{\frac{P}{\rho A}} \frac{1}{l}, \\
& \hat{\omega}=\omega \sqrt{\frac{\rho A L^{2}}{P}}, \hat{v}=v \sqrt{\frac{\rho A}{P}}, \mu=\sqrt{\frac{E A}{P}}, \\
& \alpha=\sqrt{\frac{\kappa G A}{P}}, \beta=A l \sqrt{\frac{\kappa G}{P I}} .
\end{aligned}
$$

By using the material time derivative in the shape

$$
\frac{\mathrm{d}}{\mathrm{d} t}=\frac{\partial}{\partial t}+\frac{\partial}{\partial x} v, \frac{\mathrm{d}^{2}}{\mathrm{~d} t^{2}}=\frac{\partial^{2}}{\partial t^{2}}+2 v \frac{\partial^{2}}{\partial t \partial x}+\frac{\partial^{2}}{\partial x^{2}} v^{2}
$$

As well as dimensionless variables and parameters, the equations [20] follows:

$$
\begin{aligned}
& u,_{t t}+2 v u,_{x t}+v,,_{t}\left(1+u,_{x}\right)+ \\
& \left(v^{2}-\mu^{2}\right) u,,_{x x}-\mu^{2} w,_{x x} w,_{x}=0, \\
& w,_{t t}+2 v w,_{x t}+v,,_{t} w,_{x}+\left(v^{2}-1\right) w,_{x x}- \\
& \alpha^{2}\left(w,,_{x x}-\psi,,_{x}\right)-\mu^{2}\left(w,_{x x} u,_{x}+\right. \\
& \left.+\frac{3}{2} w,_{x x} w,_{x}^{2}+w,_{x} u,_{x x}\right)=0, \\
& \psi,_{t t}+2 v \psi,,_{x t}+v,_{t} \psi,,_{x}+ \\
& \left(v^{2}-\mu^{2}\right) \psi,,_{x x}-\beta^{2}\left(w,,_{x}-\psi\right)=0 .
\end{aligned}
$$

In the Eqs. $(6) \div(8)$ the mark (,) in the index preceding $x$ or $t$ denotes the partial derivatives with respect to $x$ and $t$ and the mark $(\hat{)})$ is not used for the sake of brevity. These equations are coupled via the quadratic nonlinear terms. Introducing the new transformations with small dimensionless real number $\varepsilon$, denoting the small but finite transverse and angular deformation of the beam

$$
\hat{w}=\frac{w}{\sqrt{\varepsilon}}, \hat{\psi}=\frac{\psi}{\sqrt{\varepsilon}}
$$


it is possible, by setting all the longitudinal variables to zero, transform Eq. (7) to so called nonlinear partial differential equation:

$$
\begin{aligned}
& w,_{t t}+2 v w,_{x t}+v,{ }_{t} w,_{x}+\left(v^{2}-1\right) w,_{x x}- \\
& -\alpha^{2}\left(w,,_{x x}-\psi,,_{x}\right)=\frac{3}{2} \varepsilon \mu^{2} w,_{x x} w,_{x}^{2} .
\end{aligned}
$$

The second possibility for the uncoupling of transversal from longitudinal motion is to use quasi static stretch assumption. In that approach all the time derivatives in (6) should be neglected and the Eq. (6) further resolves by variable $u(x, t)$. After the satisfying boundary conditions, the solution for $u(x, t)$ and its partial derivatives should be replaced in (7). The new shape of the Eq. (7), so called integro - partial differential equation, in which the longitudinal displacement field is taken into account, looks like:

$$
\begin{aligned}
& w,_{t t}+2 v w,_{x t}+v,_{t} w,_{x}+\left(v^{2}-1\right) w,_{x x}- \\
& -\alpha^{2}\left(w,_{x x}-\psi,,_{x}\right)=\frac{1}{2} \varepsilon \mu^{2} w,_{x x} \int_{0}^{1} w,_{x}^{2} \mathrm{~d} x .
\end{aligned}
$$

The Eq. (8) remains the same in the case of integro partial differential equation as well as nonlinear partial differential equation.

\section{Method of multiple scales}

In purpose to solve two sets of partial differential equations ((8) and (10) in the case of nonlinear partial differential equation as well as (8) and (11) in the case of integro - partial differential equation), the analytical method - Method of multiple scales is used. The first order uniform approximation is used:

$$
\begin{aligned}
& w(x, t, \varepsilon)=w_{0}\left(x, T_{0}, T_{1}\right)+\varepsilon w_{1}\left(x, T_{0}, T_{1}\right)+\ldots, \\
& \psi(x, t, \varepsilon)=\psi_{0}\left(x, T_{0}, T_{1}\right)+\varepsilon \psi_{1}\left(x, T_{0}, T_{1}\right)+\ldots
\end{aligned}
$$

where $T_{0}=t$ represents fast and $T_{1}=\varepsilon t$ a slow scale. In this paper the perturbation of bandsaw velocity is assumed as harmonic change about the constant mean velocity $v_{0}$ :

$$
v(t)=v_{0}+\varepsilon v_{1} \sin (\Omega t)
$$

and the following expressions by $\varepsilon^{0}$ are obtained:

$$
\begin{aligned}
& w_{0},{ }_{T 0 T 0}+2 v_{0} w_{0}, x_{T 0}+\left(v_{0}^{2}-1\right) w_{0}, x_{x x}- \\
& -\alpha^{2}\left(w_{0},{ }_{x x}-\psi_{0},{ }_{x}\right)=0, \\
& \psi_{0}, T 0 T 0+2 v_{0} \psi_{0},{ }_{x T 0}+\left(v_{0}^{2}-\mu^{2}\right) \psi_{0},{ }_{x x}- \\
& -\beta^{2}\left(w_{0},{ }_{x}-\psi_{0}\right)=0,
\end{aligned}
$$

while the expressions by $\varepsilon^{1}$ for the integro - partial differential equation are:

$$
\begin{aligned}
& w_{1}, T_{T 0 T}+2 v_{0} w_{1}, x_{T 0}+\left(v_{0}^{2}-1\right) w_{1}, x_{x}-\alpha^{2}\left(w_{1}, x_{x}-\psi_{1}, x\right)= \\
& =-2 w_{0},{ }_{T 1 T 0}-2 v_{0} w_{0},{ }_{x T 1}-v_{1} \Omega w_{0},{ }_{x} \cos (\Omega t)- \\
& -2 v_{1} \Omega w_{0},{ }_{x T 0} \sin (\Omega t)-2 v_{0} v_{1} w_{0},{ }_{x x} \sin (\Omega t)+ \\
& +\frac{1}{2} \mu^{2} w_{0},{ }_{x x} \int_{0}^{1} w_{0}^{2},{ }_{x} \mathrm{~d} x \text {, } \\
& \psi_{1, T 0 T 0}+2 v_{0} \psi_{1, x T 0}+\left(v_{0}^{2}-\mu^{2}\right) \psi_{1}, x_{x}-\beta^{2}\left(w_{1}, x_{x x}-\psi_{1}, x_{x}\right)= \\
& -2 \psi_{0},{ }_{T 1 T 0}-2 v_{0} \psi_{0},{ }_{x T 1}-v_{1} \Omega \psi_{0},{ }_{x} \cos (\Omega t)- \\
& -2 v_{1} \psi_{0}, x_{x T 0} \sin (\Omega t)-2 v_{0} v_{1} \psi_{0}, x_{x x} \sin (\Omega t) \text {. }
\end{aligned}
$$

For the sake of brevity, the expressions by $\varepsilon^{1}$ for nonlinear partial differential equation (Eqs. (8) and (10)) are not written. The expression by $\varepsilon^{0}$ is the same for both considered cases.

\subsection{Exact solution of the linear problem}

The solution for the set of Eqs. (14) and (15) can be assumed as:

$$
\begin{aligned}
& w_{0}\left(x, T_{0}, T_{1}\right)=\sum_{n=1}^{\infty} A_{n}\left(T_{1}\right) e^{i \omega_{n} T_{0}} w_{n}(x)+c c, \\
& \psi_{0}\left(x, T_{0}, T_{1}\right)=\sum_{n=1}^{\infty} A_{n}\left(T_{1}\right) e^{i \omega_{n} T_{0}} \psi_{n}(x)+c c .
\end{aligned}
$$

In the previous equation $A_{n}\left(T_{1}\right)$ denotes the $n^{\text {th }}$ amplitude, $\omega_{n}$ the $n^{\text {th }}$ dimensionless natural frequency and $w_{n}(x)$ and $\psi_{n}(x)$ the $n^{\text {th }}$ complex mode shapes corresponding to transverse and angular vibrations. Also $c c$ denotes the complex conjugate member. By inserting solution (18) in the linear part of perturbed equation (equations 14 and 15) the following coupled set of partial differential equations can be obtained:

$$
\begin{aligned}
& -\omega_{n}^{2} w_{n}(x)+2 i v_{0} \omega_{n} w_{n}(x)_{x}+\left(v_{0}^{2}-1\right) w_{n}(x)_{x_{x x}}- \\
& -\alpha^{2}\left(w_{n}(x)_{x_{x}}-\psi_{n}(x)_{x}\right)=0, \\
& -\omega_{n}^{2} \psi_{n}(x)+2 i v_{0} \omega_{n} \psi_{n}(x)_{x_{x}}+\left(v_{0}^{2}-\mu^{2}\right) \psi_{n}(x)_{x_{x x}}- \\
& -\beta^{2}\left(w_{n}(x)_{x}-\psi_{n}(x)\right)=0 .
\end{aligned}
$$

Eqs. (19) and (20) are coupled and they can be decoupled with the following procedure: e.g. the Eq. (19) can be solved for $\psi_{n}(x),{ }_{x}$ and the differentiation till the third order can be calculated. After the Eq. (20) is differentiated with respect to $x$, earlier mentioned derivations should be finally inserted in. The result of this procedure is the following uncoupled equation

$$
\begin{aligned}
& n_{5} w_{n}(x),{ }_{x x x x}+n_{4} w_{n}(x),,_{x x x}+n_{3} w_{n}(x),{ }_{x x}+ \\
& +n_{2} w_{n}(x),{ }_{x}+n_{1} w_{n}(x)=0,
\end{aligned}
$$

In the similar manner the uncoupled Eq. (22) can be derived:

$$
\begin{aligned}
& n_{5} \psi_{n}(x),{ }_{x x x x}+n_{4} \psi_{n}(x),,_{x x x}+n_{3} \psi_{n}(x),{ }_{x x}+ \\
& +n_{2} \psi_{n}(x),{ }_{x}+\psi_{1} w_{n}(x)=0 .
\end{aligned}
$$


In the Eqs. (21) and (22), the following coefficients appear:

$$
\begin{aligned}
& n_{1}=\omega_{n}^{2}\left(\beta^{2}-\omega_{n}^{2}\right), n_{2}=4 i v_{0} \omega_{n}^{3}-2 i \beta^{2} v_{0} \omega_{n}, \\
& n_{3}=\omega_{n}^{2}\left(6 v_{0}^{2}-1-\alpha^{2}-\mu^{2}\right), \\
& n_{4}=2 i v_{0} \omega_{n}\left(2 v_{0}^{2}-1-\alpha^{2}-\mu^{2}\right), \\
& n_{5}=\left(\mu^{2}-v_{0}^{2}\right)\left(v_{0}^{2}-1-\alpha^{2}\right) .
\end{aligned}
$$

The solution of Eq. (22) is a sum of four products of constants and complex exponentials, which can be written as

$$
w_{n}(x)=C_{1} e^{i \lambda_{1} x}+C_{2} e^{i \lambda_{2} x}+C_{3} e^{i \lambda_{3} x}+C_{4} e^{i \lambda_{4} x}
$$

and

$$
\psi_{n}(x)=D_{1} e^{i \lambda_{1} x}+D_{2} e^{i \lambda_{2} x}+D_{3} e^{i \lambda_{3} x}+D_{4} e^{i \lambda_{4} x} .
$$

The connection between constants $C_{i}$ and $D_{i}$ is nonlinear operator $H_{j}$

$D_{i}=H_{j} C_{i}, \quad i=1 \ldots .4$

which value one might obtain using the Eqs. (24), (25) and (19) or (20):

$$
\begin{aligned}
& H_{j}=\frac{i}{\alpha^{2} \lambda_{j}}\left(\lambda_{j}^{2}\left(1+\alpha^{2}-v_{0}^{2}\right)-2 v_{0} \omega_{n} \lambda_{j}-\omega_{n}^{2}\right), \\
& j=1 \ldots 4
\end{aligned}
$$

Finally, substituting the solution (24) into the uncoupled Eq. (21), the following set of polynomial equations might be obtained:

$$
n_{5} \lambda_{k}^{4}-i n_{4} \lambda_{k}^{3}+n_{3} \lambda_{k}^{2}+i n_{2} \lambda_{k}+n_{1}=0, \quad k=1 \ldots 4(28)
$$

\subsubsection{Boundary conditions}

The vibration natural frequencies as well as its modes of vibration depend on the travelling beam boundary conditions. In this paper the hybrid boundary condition, which consists of simple supports with torsional springs characterized with different stiffness on the left $\left(k_{l}\right)$ and on the right end $\left(k_{r}\right)$ of Timoshenko beam, is used. This boundary condition can be represented as:

$$
\begin{aligned}
& w_{n}(0)=w_{n}(1)=0, \psi_{n}(0),{ }_{x}-k_{l} \psi_{n}(0)=0, \\
& \psi_{n}(1),_{x}+k_{r} \psi_{n}(1)=0
\end{aligned}
$$

Connected with specified boundary conditions, the eigenmatrix $[\boldsymbol{G}]$ of the system can be set:

$$
[\boldsymbol{G}]=\left[\begin{array}{cccc}
1 & e^{i \lambda_{1}} & H_{1}\left(-k_{l}+i \lambda_{1}\right) & H_{1} e^{i \lambda_{1}}\left(k_{r}+i \lambda_{1}\right) \\
1 & e^{i \lambda_{2}} & H_{2}\left(-k_{l}+i \lambda_{2}\right) & H_{2} e^{i \lambda_{2}}\left(k_{r}+i \lambda_{2}\right) \\
1 & e^{i \lambda_{3}} & H_{3}\left(-k_{l}+i \lambda_{3}\right) & H_{3} e^{i \lambda 3}\left(k_{r}+i \lambda_{3}\right) \\
1 & e^{i \lambda_{4}} & H_{4}\left(-k_{l}+i \lambda_{4}\right) & H_{4} e^{i \lambda_{4}}\left(k r+i \lambda_{4}\right)
\end{array}\right]^{\mathrm{T}}
$$

Non-trivial solutions of the system matrix can be obtained by developing its determinant and equalizing obtained expression by zero:

$$
\begin{aligned}
& e^{i\left(\lambda_{1}+\lambda_{4}\right)}\left(k_{l}\left(H_{2}-H_{3}\right)+i\left(H_{3} \lambda_{3}-H_{2} \lambda_{2}\right)\right) \\
& \left(k_{r}\left(H_{1}-H_{4}\right)+i\left(H_{1} \lambda_{1}-H_{4} \lambda_{4}\right)\right)+e^{i\left(\lambda_{3}+\lambda_{4}\right)} \\
& \left(k_{l}\left(H_{1}-H_{2}\right)+i\left(H_{2} \lambda_{2}-H_{1} \lambda_{1}\right)\right) \\
& \left(k_{r}\left(H_{3}-H_{4}\right)+i\left(H_{3} \lambda_{3}-H_{4} \lambda_{4}\right)\right)+e^{i\left(\lambda_{2}+\lambda_{4}\right)} \\
& \left(k_{l}\left(H_{1}-H_{3}\right)+i\left(H_{3} \lambda_{3}-H_{1} \lambda_{1}\right)\right) \\
& \left(k_{r}\left(H_{4}-H_{2}\right)+i\left(H_{4} \lambda_{4}-H_{2} \lambda_{2}\right)\right)+e^{i\left(\lambda_{2}+\lambda_{3}\right)} \\
& \left(i k_{l}\left(H_{1}-H_{4}\right)+\left(H_{1} \lambda_{1}-H_{4} \lambda_{4}\right)\right) \\
& \left(i k_{r}\left(H_{3}-H_{2}\right)+\left(H_{2} \lambda_{2}-H_{3} \lambda_{3}\right)\right)+e^{i\left(\lambda_{1}+\lambda_{2}\right)} \\
& \left(i k_{l}\left(H_{3}-H_{4}\right)+\left(H_{3} \lambda_{3}-H_{4} \lambda_{4}\right)\right) \\
& \left(i k_{r}\left(H_{2}-H_{1}\right)+\left(H_{1} \lambda_{1}-H_{2} \lambda_{2}\right)\right)+e^{i\left(\lambda_{1}+\lambda_{3}\right)} \\
& \left(i k_{l}\left(H_{4}-H_{2}\right)+\left(H_{4} \lambda_{4}-H_{2} \lambda_{2}\right)\right) \\
& \left.\left(i k_{r}\left(H_{3}-H_{1}\right)+\left(H_{1} \lambda_{1}-H_{3} \lambda_{3}\right)\right)\right)=0 .
\end{aligned}
$$

The unknown ratios of coefficients $C_{2} \ldots C_{4}$ and $C_{1}$ might finally be found by matrix transformation (row reduce) of the matrix $[\boldsymbol{G}]$. By this type of matrix transformation, the following ratios between constants are obtained:

$$
\begin{aligned}
& \frac{C_{2}}{C_{1}}=\left(e^{i \lambda_{4}}\left(k_{l}\left(H_{3}-H_{1}\right)+i\left(H_{1} \lambda_{1}-H_{3} \lambda_{3}\right)\right)+\right. \\
& +e^{i \lambda 1}\left(k_{l}\left(H_{4}-H_{3}\right)+i\left(H_{3} \lambda_{3}-H_{4} \lambda_{4}\right)\right)+ \\
& \left.e^{i \lambda_{3}}\left(k_{l}\left(H_{1}-H_{4}\right)+i\left(H_{4} \lambda_{4}-H_{1} \lambda_{1}\right)\right)\right) / R \\
& \frac{C_{3}}{C_{1}}=-\left(e^{i \lambda_{4}}\left(k_{l}\left(H_{2}-H_{1}\right)+i\left(H_{1} \lambda_{1}-H_{2} \lambda_{2}\right)\right)+\right. \\
& +e^{i \lambda 1}\left(k_{l}\left(H_{4}-H_{2}\right)+i\left(H_{2} \lambda_{2}-h_{4} \lambda_{4}\right)\right)+ \\
& \left.e^{i \lambda 2}\left(k_{l}\left(H_{1}-H_{4}\right)+i\left(H_{4} \lambda_{4}-H_{1} \lambda_{1}\right)\right)\right) / R
\end{aligned}
$$

$\frac{C_{4}}{C_{1}}=\left(e^{i \lambda_{3}}\left(k_{l}\left(H_{2}-H_{1}\right)+i\left(H_{1} \lambda_{1}-H_{2} \lambda_{2}\right)\right)+\right.$

$+e^{i \lambda 1}\left(k_{l}\left(H_{3}-H_{1}\right)+i\left(H_{2} \lambda_{2}-H_{3} \lambda_{3}\right)\right)+$

$\left.e^{i \lambda 2}\left(k_{l}\left(H_{1}-H_{3}\right)+i\left(H_{3} \lambda_{3}-H_{1} \lambda_{1}\right)\right)\right) / R$

where:

$$
\begin{aligned}
& R=e^{i \lambda_{4}}\left(k_{l}\left(H_{2}-H_{3}\right)+i\left(H_{3} \lambda_{3}-H_{2} \lambda_{2}\right)\right)+ \\
& +e^{i \lambda 3}\left(k_{l}\left(h_{4}-h_{2}\right)+i\left(H_{2} \lambda_{2}-H_{4} \lambda_{4}\right)\right)+ \\
& e^{i \lambda 2}\left(k_{l}\left(H_{3}-H_{4}\right)+i\left(H_{4} \lambda_{4}-H_{3} \lambda_{3}\right)\right) .
\end{aligned}
$$

The numerical procedure for obtaining the dimensionless natural frequencies $\omega_{n}$ as well as belonging modes consists of a few steps. In the first step, the numerical value of dimensionless natural frequency should be assumed and corresponding coefficients $n_{1} \ldots n_{5}$ from Eq. (23) are calculated. In the next step, the values of $\lambda_{\mathrm{k}}$ are also calculated, by solving of polynomial Eqs. (28). In continuation, the values of $H_{j}$ from (27) are 
calculated and the mentioned procedure is repeated till all the calculated values from above mentioned equations, for the specific $\omega_{n}$, are satisfied (within the appropriate numerical tolerances). If the Eq. (31) is satisfied in that way, the assumed value of $\omega_{n}$ is true dimensionless natural frequency (Fig. 2) and the belonging mode shape (Fig. 3), through the Eqs. $(32) \div(35)$ can be calculated.

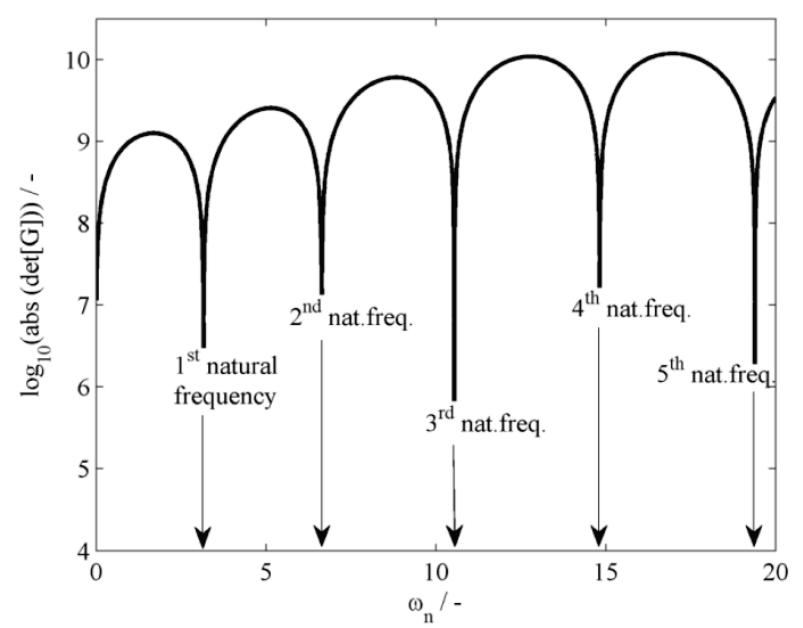

Figure 2 Dimensionless natural frequencies of travelling beam

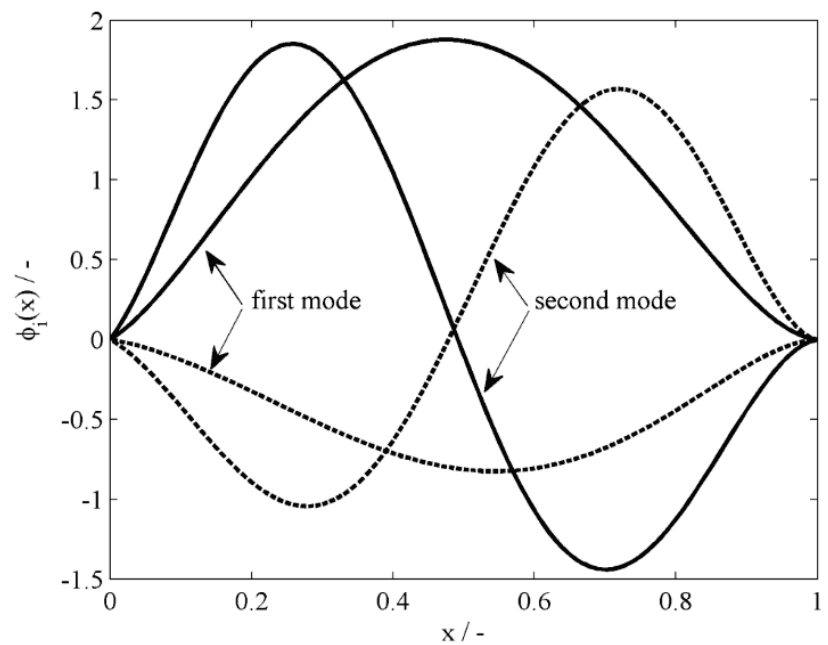

Figure 3 Mode shapes of travelling beam

\subsection{Approximate solution of the nonlinear problem}

In the case when any excitation parameter, e.g. the bandsaw axial velocity variation frequency $\Omega$, approaches doubled value of any natural frequency of the system, principal parametric resonance may occur. With the goal of exploring the $n^{\text {th }}$ principal resonance, under the assumption that there is no internal resonance or combination resonance, it is possible to include only the considering $n^{\text {th }}$ mode of vibration:

$$
\begin{aligned}
& w_{0}\left(x, T_{0}, T_{1}\right)=A_{n}\left(T_{1}\right) e^{i \omega_{n} T_{0}} w_{n}(x)+c c, \\
& \psi_{0}\left(x, T_{0}, T_{1}\right)=A_{n}\left(T_{1}\right) e^{i \omega_{n} T_{0}} \psi_{n}(x)+c c .
\end{aligned}
$$

The deviation of variation frequency $\Omega$ from the double amount of the $n^{\text {th }}$ natural frequency $\omega_{n}$ is denoted by so called detuning parameter
$\Omega=2 \omega_{n}+\varepsilon \sigma$

Using the Eqs. (36) and (37), it is possible to rewrite Eqs. (16) and (17) as:

$$
\begin{aligned}
& w_{1}, T 0 T 0+2 v_{0} w_{1}, x T 0+\left(v_{0}^{2}-1\right) w_{1}, x x-\alpha^{2}\left(w_{1}, x_{x}-\right. \\
& \left.-\psi_{1,{ }_{x}}\right)=e^{i \omega_{n} T_{0}}\left(-2 i \omega_{n} w_{n}(x) A_{N, T 1}-\right. \\
& -2 v_{0} w_{n, x}(x) A_{N, T 1}+\mu^{2} A_{N}{ }^{2} \bar{A}_{N} w_{n, x x}(x)+ \\
& +\int_{0}^{1} w_{n, x}(x) \bar{w}_{n, x}(x) \mathrm{d} x+\frac{1}{2} \mu^{2} A_{N}{ }^{2} \bar{A}_{N} w_{n, x x}(x) \\
& \left.\int_{0}^{1}\left(w_{n, x}(x)\right)^{2} \mathrm{~d} x\right)+e^{i \omega_{n} T_{0}} e^{i \sigma T_{1}} \bar{A}_{N} \\
& \left(-\frac{1}{2} v_{1} \Omega \bar{w}_{n, x}(x)+v_{1} \omega_{n} \bar{w}_{n, x}(x)+i v_{0} v_{1} \bar{w}_{n, x x}(x)\right) \\
& \psi_{1},{ }_{T 0 T 0}+2 v_{0} \psi_{1},{ }_{x T 0}+\left(v_{0}^{2}-\mu^{2}\right) \psi_{1},{ }_{x x}- \\
& -\beta^{2}\left(w_{1},{ }_{x x}-\psi_{1},{ }_{x}\right)=e^{i \omega_{n} T_{0}}\left(-2 i \omega_{n} w_{n}(x) A_{N, T 1}-\right. \\
& \left.-2 v_{0} w_{n, x}(x) A_{N, T 1}\right)+e^{i \omega_{n} T_{0}} e^{i \sigma T_{1}} \bar{A}_{N} \\
& \left(-\frac{1}{2} v_{1} \Omega \bar{w}_{n, x}(x)+v_{1} \omega_{n} \bar{w}_{n, x}(x)+i v_{0} v_{1} \bar{w}_{n, x x}(x)\right) \text {. }
\end{aligned}
$$

By using the following substitutions

$$
\begin{aligned}
& w_{1}(x, t)=\hat{w}_{1}\left(x, T_{1}\right) e^{i \omega_{n} T_{0}}+c c \\
& \psi_{1}(x, t)=\hat{\psi}_{1}\left(T_{1}\right) e^{i \omega_{n} T_{0}}+c c .
\end{aligned}
$$

without a remark $\left(^{\wedge}\right)$, it is possible to obtain the following set of differential equations

$$
\begin{aligned}
& -\omega_{n} w_{1}+2 i v_{0} \omega_{n} w_{1, x}+\left(v_{0}{ }^{2}-1\right) w_{1, x x}- \\
& -\alpha^{2}\left(w_{1, x x}-\psi_{1, x}\right)=-2 i \omega_{n} w_{n}(x) A_{N, T 1}- \\
& -2 v_{0} w_{n, x}(x) A_{N, T 1}+\mu^{2} A_{N}{ }^{2} \bar{A}_{N} w_{n, x x}(x) \\
& +\int_{0}^{1} w_{n, x}(x) \bar{w}_{n, x}(x) \mathrm{d} x+\frac{1}{2} \mu^{2} A_{N}{ }^{2} \bar{A}_{N} \\
& w_{n, x x}(x) \int_{0}^{1}\left(w_{n, x}(x)\right)^{2} \mathrm{~d} x+e^{i \sigma T_{1}} \bar{A}_{N} \\
& \left(-\frac{1}{2} v_{1} \Omega \bar{w}_{n, x}(x)+v_{1} \omega_{n} \bar{w}_{n, x}(x)+i v_{0} v_{1} \bar{w}_{n, x x}(x)\right) \\
& -\omega_{n} \psi_{1}+2 i v_{0} \omega_{n} \psi_{1, x}+\left(v_{0}{ }^{2}-\mu^{2}\right) \psi_{1, x x}- \\
& -\beta^{2}\left(w_{1, x}-\psi_{1}\right)=-2 i \omega_{n} \psi_{n}(x) A_{N, T 1}- \\
& -2 v_{0} \psi_{n, x}(x) A_{N, T 1}+e^{i \sigma T_{1}} \bar{A}_{N} \\
& \left(-\frac{1}{2} v_{1} \Omega \bar{\psi}_{n, x}(x)+v_{1} \omega_{n} \bar{\psi}_{n, x}(x)+i v_{0} v_{1} \bar{\psi}_{n, x x}(x)\right)
\end{aligned}
$$

Previous equations have a bounded solution only if a solvability condition is satisfied. The solvability condition demands that the secular term in the right hand of the Eqs. (41) and (42) is orthogonal to every solution of the homogeneous problem. In order to avoid the unbounded solution, the usage of the solvability condition from [2] i.e. distributive law of the inner product 


$$
\langle f(x), g(x)\rangle=\int_{0}^{1} f(x) \bar{g}(x) \mathrm{d} x
$$

will result in the following differential equation

$$
A_{N, T 1}-\tau \mu^{2} A_{N}^{2} \bar{A}_{N}+\chi v_{1} e^{i \sigma T_{1}} \bar{A}_{N}=0
$$

where the coefficients $\tau=\mathrm{N}_{1} / D$ and $\chi=N_{2} / D$ are defined as

$$
\begin{aligned}
& N_{1}=\int_{0}^{1} \bar{w}_{n}(x) w_{n, x x}(x) \mathrm{d} x \int_{0}^{1} w_{n, x}(x) \bar{w}_{n, x}(x) \mathrm{d} x+ \\
& +\frac{1}{2} \int_{0}^{1} \bar{w}_{n}(x) \bar{w}_{n, x x}(x) \mathrm{d} x \int_{0}^{1}\left(w_{n, x}(x)\right)^{2} \mathrm{~d} x \\
& N_{2}=\left(\frac{1}{2} \Omega-\omega_{n}\right)\left(\int_{0}^{1} \bar{w}_{n, x}(x) \bar{w}_{n}(x) \mathrm{d} x+\right. \\
& \left.+\int_{0}^{1} \bar{\psi}_{n, x}(x) \bar{\psi}_{n}(x) \mathrm{d} x\right)- \\
& -i v_{0}\left(\int_{0}^{1} \bar{w}_{n, x x}(x) \bar{w}_{n}(x) \mathrm{d} x+\int_{0}^{1} \bar{\psi}_{n, x x}(x) \bar{\psi}_{n}(x) \mathrm{d} x\right) \\
& D=2 i \omega_{n}\left(\int_{0}^{1} \bar{w}_{n}(x) w_{n}(x) \mathrm{d} x+\int_{0}^{1} \psi_{n}(x) \bar{\psi}_{n}(x) \mathrm{d} x\right)+ \\
& +2 v_{0}\left(\int_{0}^{1} \bar{w}_{n}(x) w_{n, x}(x) \mathrm{d} x+\int_{0}^{1} \psi_{n, x}(x) \bar{\psi}_{n}(x) \mathrm{d} x\right)
\end{aligned}
$$

The Eqs. $(44) \div(47)$ refer to the integro - partial differential equation model (Eqs. (11), (16) and (17)). In the case of using a nonlinear partial differential equation model (Eqs. (8) and (10)), there will be only one difference. Instead of Eq. (45) the following equation should be used

$$
\begin{aligned}
& N_{1}=3 \int_{0}^{1} \bar{w}_{n}(x) w_{n, x x}(x) w_{n, x}(x) \bar{w}_{n, x}(x) \mathrm{d} x+ \\
& +\frac{3}{2} \int_{0}^{1} \bar{w}_{n}(x)\left(w_{n, x}(x)\right)^{2} \bar{w}_{n, x x}(x) \mathrm{d} x
\end{aligned}
$$

In the procedure for obtaining a steady-state nonlinear response, which will result in a non-trivial solution for vibration amplitudes, here it is necessary to introduce the following polar form substitution

$$
A_{N}\left(T_{1}\right)=\frac{1}{2} a_{N}\left(T_{1}\right) e^{i \beta_{n}}\left(T_{1}\right)
$$

where $a_{N}$ and $\beta_{n}$ are both real. Described substitution, after separating the real and imaginary parts of the equation, leads to the following set of differential equations

$$
\begin{aligned}
& a_{N, T_{1}}=\frac{1}{4} \mu^{2} \kappa_{r} a_{N}^{3}+ \\
& +a_{N} v_{1}\left(\chi_{i} \sin \vartheta_{N}-\chi_{r} \cos \vartheta_{N}\right) \\
& \vartheta_{N, T_{1}}=\sigma-\frac{1}{2} \mu^{2} \kappa_{i} a_{N}^{2}+ \\
& +2 v_{1}\left(\chi_{r} \sin \vartheta_{N}+\chi_{i} \cos \vartheta_{N}\right)
\end{aligned}
$$

where $\theta_{N}=\sigma T_{1}-2 \beta_{N}, \tau=\tau_{r}+i \tau_{i}, \chi=\chi_{r}+i \chi_{i}$. Finally from Eqs. (50) and (51), taking into account the steadystate response, it is possible to obtain relation

$$
\sigma_{1,2}=\frac{1}{2} \mu^{2} \tau_{i} a_{N}^{2} \pm 2 \sqrt{v_{1}^{2}\left(\chi_{i}^{2}+\chi_{r}^{2}\right)-\left(\frac{1}{4} \mu^{2} \tau_{r} a_{N}^{2}\right)^{2}}
$$

Eq. (52) is an implicit equation for the amplitude of the response $a_{N}$ as a function of detuning parameter $\sigma$ which needs an iterative process for its solving. Namely, this equation can be solved numerically for the earlier known modes of vibrations in vicinity of some principal resonance (Eqs. (43) $\div(46)$ ). But these equations also depend on $\sigma$, through the connecting Eq. (37), so the iterative process should be used.

\section{$4 \quad$ Numerical examples}

In this section two numerically solved illustrative examples, connected with application of the written program solution, are represented and explained. The program code based on the theory explained in the previous sections is written in MATLAB programming environment.

\subsection{Nonlinear vibrations of travelling beam}

The first numerical example is connected with some numerical results which are earlier published in the relevant literature. Some of input data was also very useful for further calculations on the example from the industrial practice.

\subsubsection{Natural frequencies and linear vibration modes}

In this example the results of calculation of linear vibration modes, calculated by the own code are compared with the results of analytical expressions given in [24], which are based on the theory explained in [14].

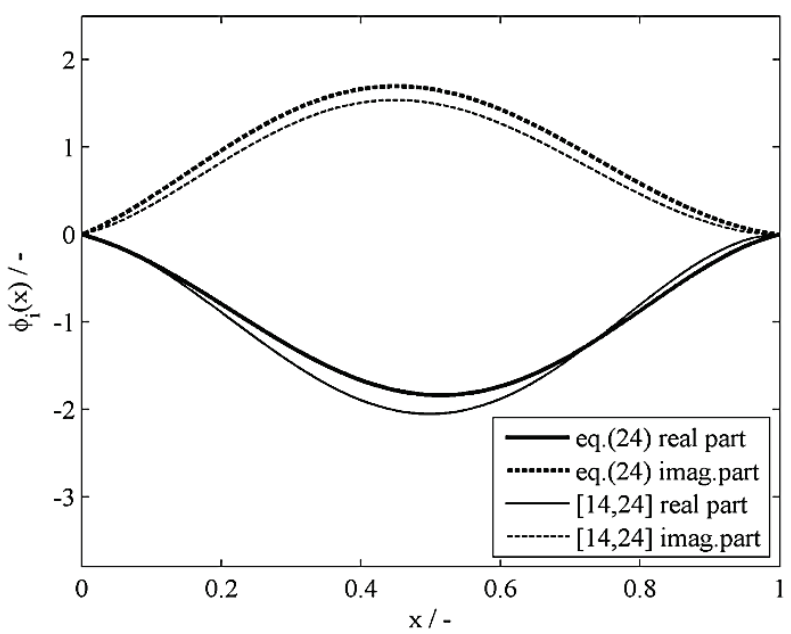

Figure 4 Comparison of real and imaginary parts of first mode shape of travelling beam calculated by Eq. $(24)$ and $[14,24]$

The material and geometric properties of the moving beam are in both cases chosen as follows: 
$E=2,1 \times 10^{11} \mathrm{~Pa}, G=7,84 \times 10^{10} \mathrm{~Pa}, \rho=7800 \mathrm{~kg} / \mathrm{m}^{3}, k=0,8$, $l=1 / \mathrm{m}, \mu=3,09, A=3,367 \times 10^{-4} \mathrm{~m}^{2}, I=1,697 \times 10^{-5} \mathrm{~m}^{4}$, $v_{0}=1, k_{l}=20 \mathrm{~N} \cdot \mathrm{m} \cdot \mathrm{rad}^{-1}, k_{r}=20000 \mathrm{~N} \cdot \mathrm{m} \cdot \mathrm{rad}^{-1}$.

Both calculations gave the slightly different first and second natural frequency $\left(\omega_{\mathrm{n} 1}=17,0163(19,14)\right.$ and $\omega_{\mathrm{n} 2}=$ $40,8237(46,911)$ with the belonging vibration modes (Fig. 4 and 5).The reason for this difference is a different approach to the material time derivative in the equation for slope of the beam cross-section $\psi$, so the Eq. (8) in the case covered by own program solution is more complicated than the equivalent equation in literature [14, 24]. Also in Figs. 4 and 5, the asymmetry of the vibration modes is caused by different torsional stiffness of the supports as well as by moving beam with specific velocity.

\subsubsection{Influence of beam mean axial velocity and axial tensions on natural frequencies}

The velocity depending natural frequencies of the beam, for the different axial tensions as well as different boundary conditions, are given in Figs. $6 \div 9$. In this example the same input parameters as well as in the previous example are used. The curves in the pictures show the trend of decreasing of dimensionless natural frequencies (4) with the increasing of beam mean velocity $v_{0}$ as well as with increasing of axial tension force $P$ which produce decrease of parameter $\mu\left(\mu_{1}=3,09, \mu_{2}=6,17\right.$, $\left.\mu_{3}=9,26, \mu_{4}=12,34, \mu_{5}=15,43\right)$. Also dimensionless natural frequencies of the beam will decrease with the softening of the supports i.e. torsional springs set in the mathematical model to simulate different boundary conditions. From this diagrams it can be also concluded that the dimensionless natural frequency curves of the travelling beams will be placed in the diagrams somewhere between curves of belonging simple-simple supported and clamped-clamped beams. It also relates to the travelling beams with hybrid boundary conditions on its ends.

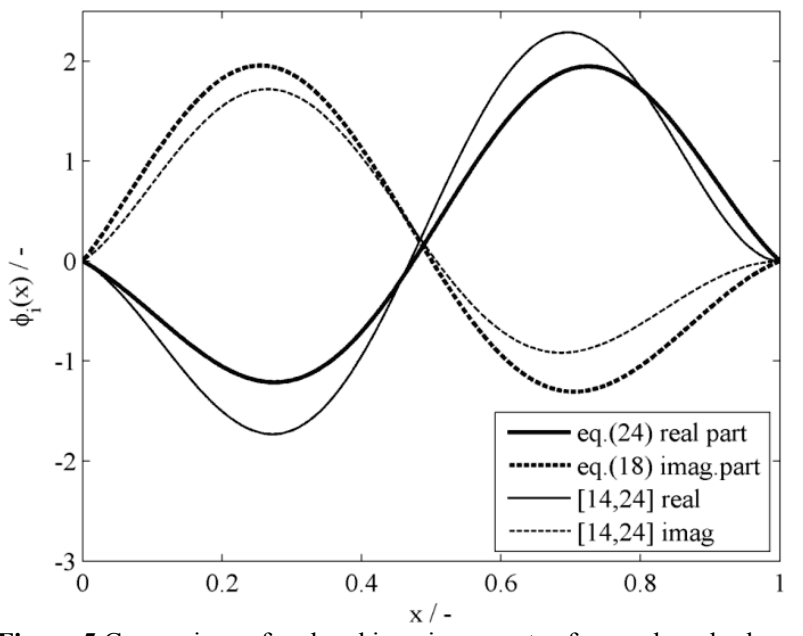

Figure 5 Comparison of real and imaginary parts of second mode shape of travelling beam calculated by Eq. (24) and [14, 24]

Also, dimensionless natural frequencies for a stationary beam are calculated by MSC.Nastran for Windows and good agreements with the presented theory, especially for first mode, can be seen in Figs. 6 to 9 .

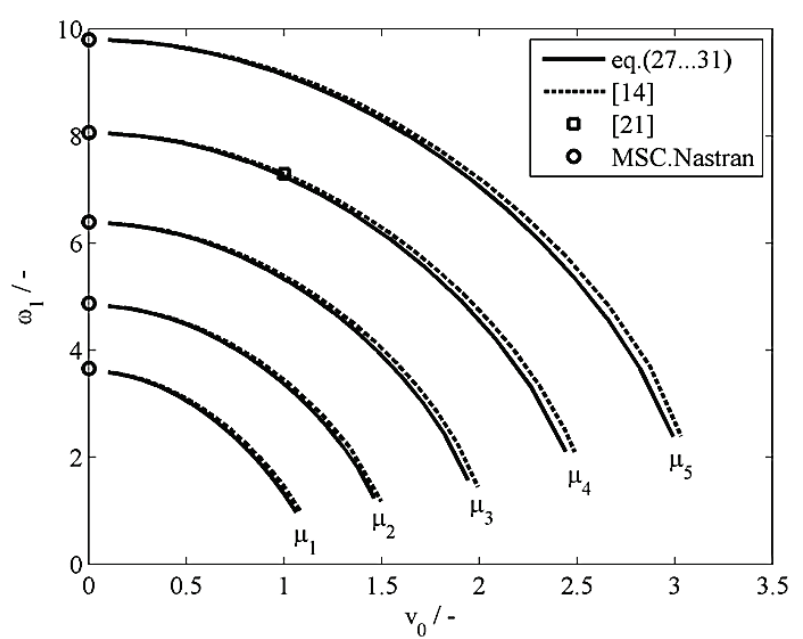

Figure 6 Dimensionless natural frequencies of first vibration mode of travelling beam (and of stationary beam - modelled by MSC. Nastran for Windows) on simple-simple supported ends loaded by different axial tension force

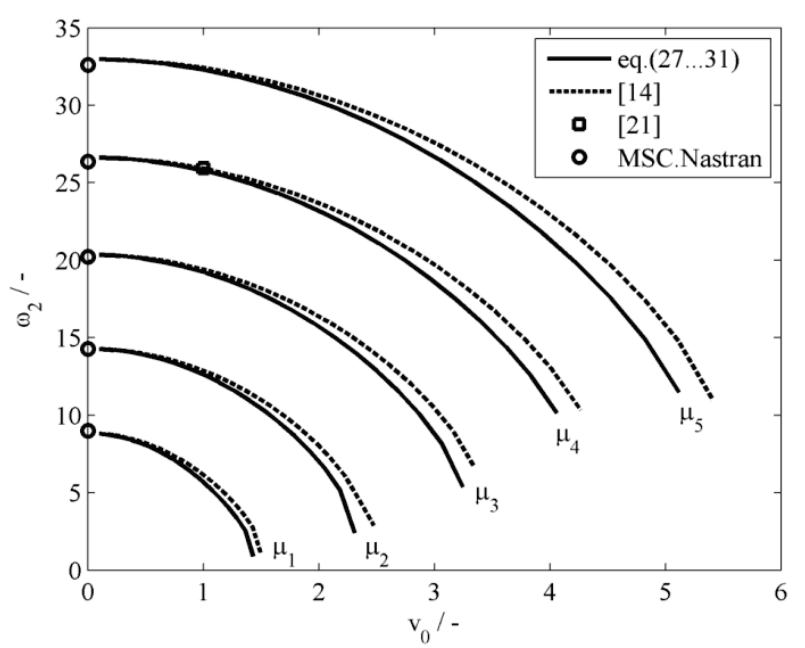

Figure 7 Dimensionless natural frequencies of second vibration mode of travelling beam (and of stationary beam - modelled by MSC. Nastran for Windows) on simple-simple supported ends loaded by different axial tension force

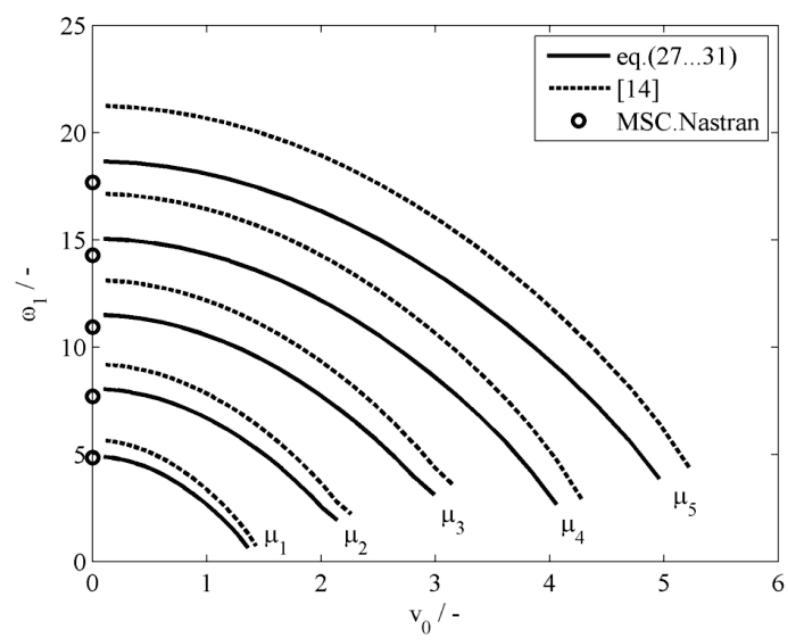

Figure 8 Dimensionless natural frequencies of first vibration mode of travelling beam (and of stationary beam - modelled by MSC. Nastran for Windows) on clamped-clamped supported ends loaded by different axial tension force 


\subsubsection{Amplitudes of response of the travelling beam at principal parametric resonance}

According to the expression (52) the nonlinear amplitudes $\alpha_{N}$ of the steady state response of travelling Timoshenko beam depend on the detuning parameter $\sigma$, but also on the wide range of parameters, such as velocity of the blade $v_{0}$, length of the beam (between to supports) $l$ as well as axial tension of the beam $P$. These relations are connected with variables which appear in Eqs. (45) $\div(48)$ and the final result is bending of the shape of resonant curve, which is shown in Figs. 10 and 11.

The input parameters for the simple-simple supported beam from this example are the same as those in earlier examples, with only one exception that value of dimensionless parameter $\mu$ is set to 12,34 .

From Figs. 10 and 11 it can be concluded that the resonant curves related to two different approaches (nonlinear partial differential equations vs. integro partial differential equations) are similar qualitatively but not quantitatively. The approach with integro - partial differential equations corrects the bending of the resonant curves i.e. gives the higher values of resonant amplitudes. The values of resonant amplitudes are a bit smaller for the second principal resonance (Fig. 10) in relationship to the first principal resonance (Fig. 11). Also earlier mentioned approach given in [21] gives considerable lower resonant amplitudes in comparison with amplitudes calculated with authors own program solution.

The correlation between members of the Eq. (13) due to changes of the beam's velocity can be obtained by performing an iteration procedure. Its goal is to calculate final value of $\Omega$, which has to satisfy Eqs. (37), (43) $\div(46)$ and (51). For input variables of $\varepsilon v_{1}, v_{0}$ as well as selected mode shape, the 3-D graphs shown in Figs. 12 and 13 can be obtained. For such moving beams, Öz and Pakdemirli [22] commented the stable and unstable regions on similar diagrams, depicting the area between two surfaces as unstable region, while the areas outside the two surfaces should be stable.

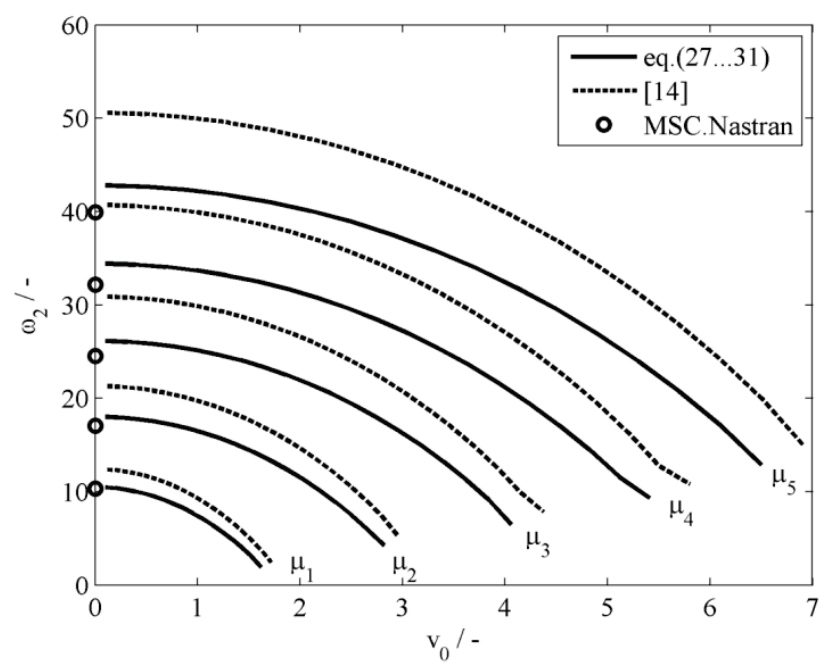

Figure 9 Dimensionless natural frequencies of second vibration mode of travelling beam (and of stationary beam - modelled by MSC. Nastran for Windows) on clamped-clamped supported ends loaded by different axial tension force

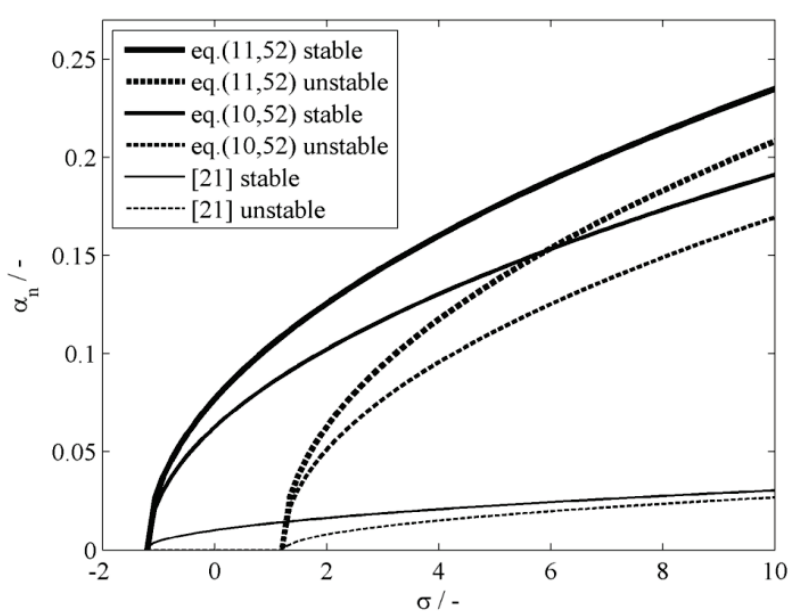

Figure 10 Comparison of nonlinear amplitudes of vibrations in the first principle parametric resonance for the nonlinear partial differential equations approach, integro - partial differential equations approach and approach from [21]

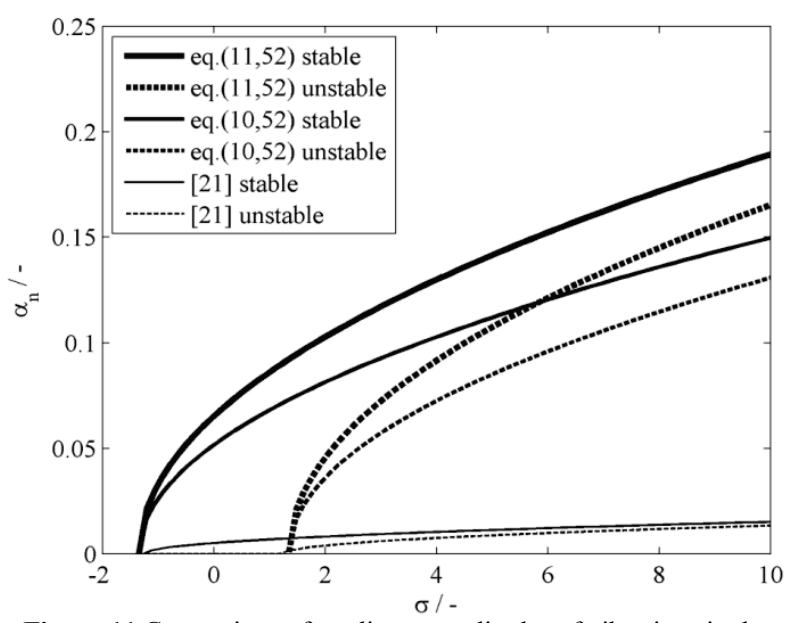

Figure 11 Comparison of nonlinear amplitudes of vibrations in the second principle parametric resonance for the nonlinear partial differential equations approach, integro - partial differential equations approach and approach from [21]

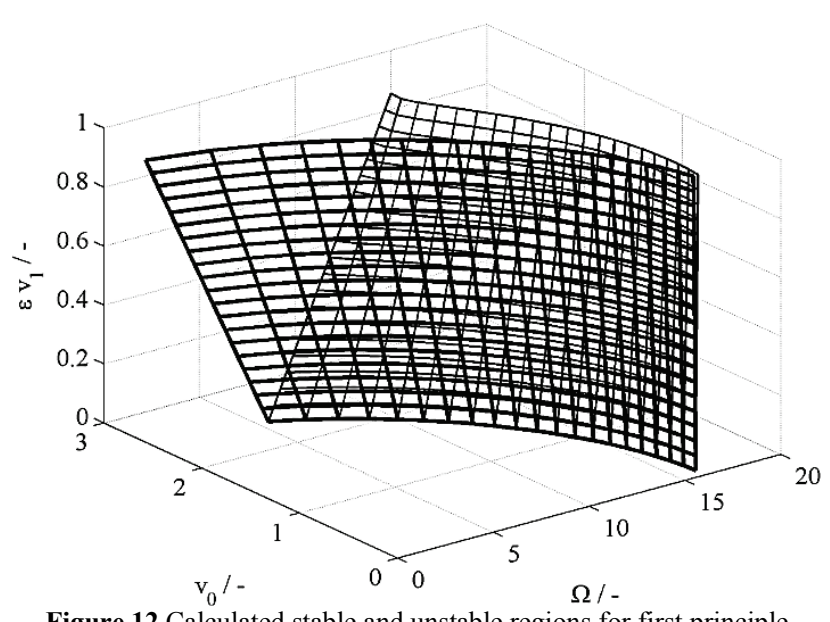

Figure 12 Calculated stable and unstable regions for first principle parametric resonance from [21]

\subsection{Example from industrial practice-estimation of parameters for the woodworking bandsaw}

In this example, the mathematical model of nonlinear vibrations of bandsaw from the sawmill Potok, Čabar, Fig. 14, is explored. As a cutting device, the UDDEHOLM band [26] with the following material 
characteristics is used: Young modulus $E=2,1 \times 10^{11} \mathrm{~Pa}$, shear modulus $G=7,84 \times 10^{10} \mathrm{~Pa}$, mass density $\rho=7800$ $\mathrm{kg} / \mathrm{m}^{3}$, while geometrical characteristics of that band are: width of the blade $b=0,135 \mathrm{~m}$, thickness of the blade $h=0,0013 \mathrm{~m}\left(A=1,755 \times 10^{-4} \mathrm{~m}^{2}, I=3,198 \times 10^{-6} \mathrm{~m}^{4}\right)$ and its length $l=1 \mathrm{~m}$. Shape factor for the Timoshenko beam is chosen as $\kappa=1,25$ while axial tension in the bandsaw is $P=70000 \mathrm{~N}$.

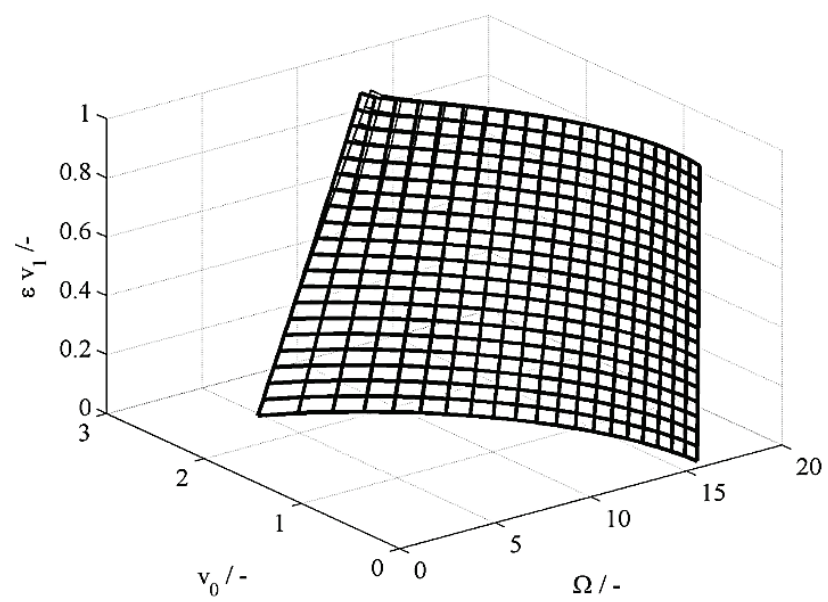

Figure 13 Calculated stable and unstable regions for first principle parametric resonance from authors own program solution

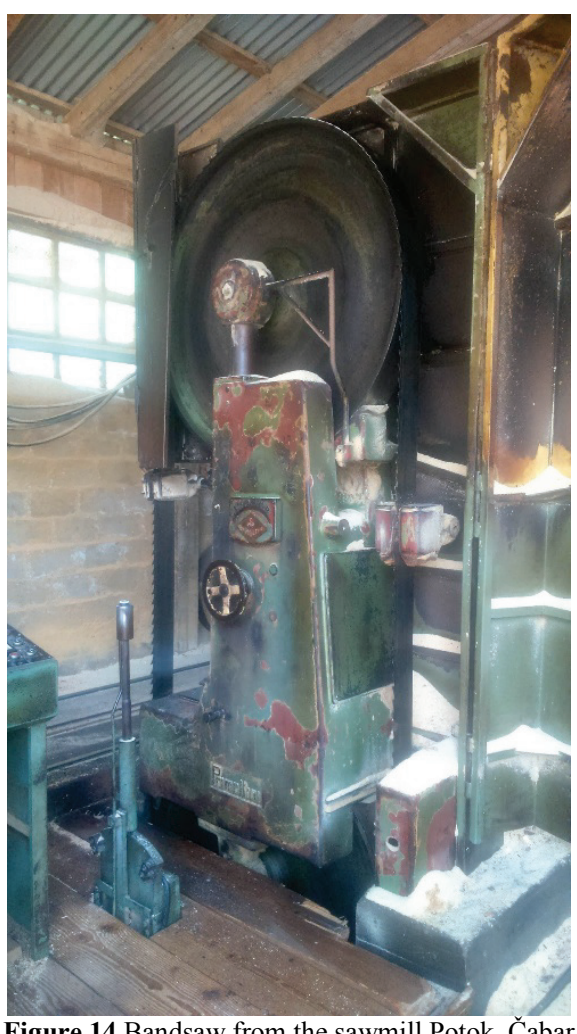

In Fig. 15 results of conducted numerical analysis of bandsaw vibrations, for the different supporting conditions, are shown. From the reason that for each vibration mode, two curves of natural frequencies are given (lower for the simple-simple support and higher for the clamped-clamped supporting condition), the natural frequencies curves connected with the hybrid supporting conditions (exploitation conditions) will be placed somewhere between these values (shadowed area). In the case that from the conditions of exploitation the cutting speed is known (here $(\sim 30 \mathrm{~m} / \mathrm{s})$, it is possible for the working conditions from the diagram in Fig. 15, to read off the natural frequencies (first ranges between 329,86 $\mathrm{Hz}$ for the simple-simple support and $675,67 \mathrm{~Hz}$ for clamped-clamped condition and second ranges between $1190,75 \mathrm{~Hz}$ for simple-simple support and1619,29 Hz for clamped-clamped boundary condition).

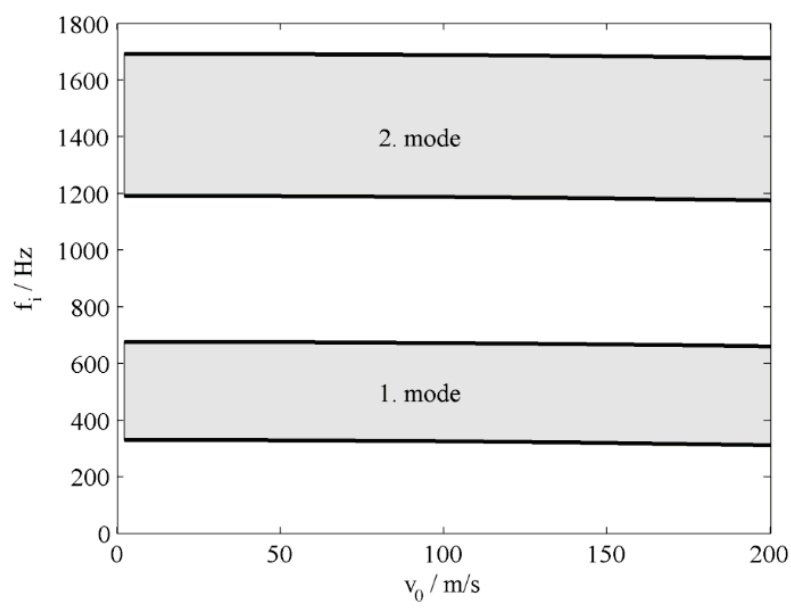

Figure 15 Estimated areas of first and second natural frequencies of woodworking bandsaw in correlation with boundary conditions (from simple-simple supports to clamped-clamped)

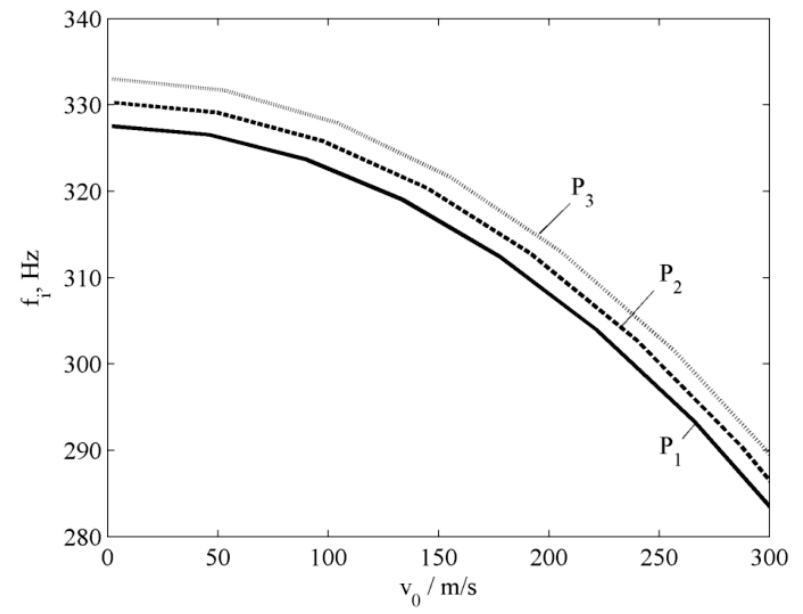

Figure 16 Influence of axial tension of travelling beam on its first natural frequency

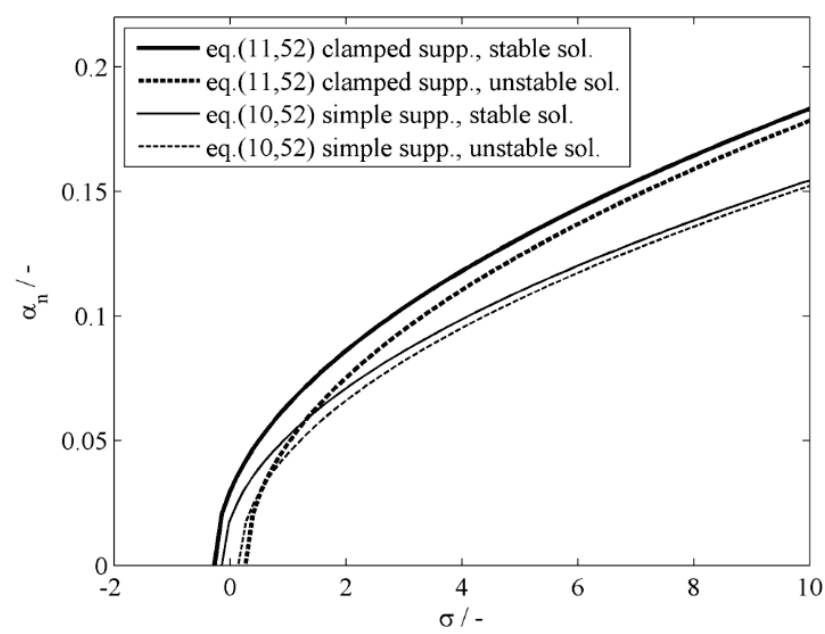

Figure 17 Comparison of the bandsaws' nonlinear amplitudes of vibrations in the first principle parametric resonance for the different boundary conditions (from simple-simple to clamped-clamped) 
In Fig. 16 the comparison of bandsaws nonlinear amplitudes of vibrations for the first principle parametric resonance for the different boundary conditions is shown. In this calculation the integro - partial differential equations approach is applied. From this approach the influence of longitudinal displacement on the transverse vibrations of axially moving Timoshenko beam, in the first principal parametric resonance, is best seen.

Also, the influence of axial tension $\left(P_{1}=60000 \mathrm{~N}\right.$, $P_{2}=70000 \mathrm{~N}$ and $\left.P_{3}=80000 \mathrm{~N}\right)$ and velocity of travelling simply supported beam on its first natural frequency can be seen in Fig. 16.

The diagram in Fig. 17 shows that the simple-simple support causes a greater inclination of resonance curve and resulting in a lower amplitude of nonlinear vibration. It is also noticeable that the area between stable (solid line) and unstable solutions (dashed curve) in this case is narrower in relation to resonance curves for the clampedclamped conditions reliance (marked in the same manner).

As in the case shown in the diagram in Fig. 15, here it should be also noted that the amplitude curve of the actual supporting boundary conditions (depending on the stiffness of the torsional springs) ranges somewhere between two stable amplitudes of nonlinear vibrations (shown with continuous lines) and between two unstable amplitudes of nonlinear vibrations (shown with dashed lines).

\section{Conclusion}

Natural frequencies and belonging modes as well as amplitudes of nonlinear principal parametric resonance of axially travelling woodworking bandsaw are numerically investigated by the method of multiple scales. The transverse motion of a travelling bandsaw, modelled as the Timoshenko beam, can be governed by a nonlinear partial-differential equation or a nonlinear integro-partialdifferential equation. The second approach takes into consideration the longitudinal displacement of the bandsaw and its influence on transverse motion. The expressions for the mode shapes in the case of hybrid supports with different torsion spring stiffness on the support points are also derived.

The investigation leads to the following conclusions: (1) Due to the different torsional stiffness of the bandsaw on the place of supports as well as the effect connected with the velocity of the bandsaw, the asymmetry of first and second vibrational mode appears. (2) Dimensionless natural frequencies decrease while real natural frequencies increase if axial tension force $P$ increases. (3) Natural frequencies of the bandsaw will decrease with the softening of the supports. (4) The approach with integro partial differential equations corrects the bending of the resonant curves i.e. gives higher values of resonant amplitudes. (5) The values of resonant amplitudes are a bit smaller for the second principal resonance in relationship to the first principal resonance. (6) Natural frequency curves of the woodworking bandsaw will be placed on the diagrams in the area between curves of belonging simple-simple supported and clamped-clamped boundary conditions. It also relates to the bandsaw with hybrid boundary conditions on its ends.
Further investigations on the proposed subject should be directed to experimental (static and dynamic) analysis of bandsaws i.e. to the estimation of their working parameters especially connected with the boundary conditions.

\section{Acknowledgements}

AdriaHub is a collaborative project funded by the European Union (EU) inside the Adriatic IPA CBC Programme, an Instrument for the Pre-Accession Assistance (IPA) of neighbor countries of Western Balkan thanks to investment in Cross-Border Cooperation (CBC) aiming at a joint economic and social development. Details in [25].

\section{References}

[1] Nayfeh, A. H.; Mook, D. T. Nonlinear Oscillattions, John Wiley and Sons, New York, 1995. DOI: 10.1002/9783527617586

[2] Nayfeh, A. H. Introduction to Perturbation Techniques, John Wiley and Sons, New York, 1993. DOI: 10.1002/zamm.19810611224

[3] Wickert, J. A.; Mote, C. D., Jr. Classical Vibration Analysis of Axially Moving Continua. // ASME Journal of Applied Mechanics, 57(1990), pp. 738-744. DOI: 10.1115/1.2897085

[4] Lee, S. Y.; Mote, C. D., Jr. A Generalized Treatment of the Energetics of Translating Continua, Part II: Beams and Fluid Conveying Pipes. // Journal of Sound and Vibration. 204, 5(1997), pp. 735-753. DOI: 10.1006/jsvi.1996.0946

[5] Chen, L-Q.; Chen, H.; Lim, C. W. Asymptotic Analysis of Axially Accelerating Viscoelastic Strings. // International Journal of Engineering Science. 46, (2008), pp. 976-985. DOI: 10.1016/j.jijengsci.2008.03.009

[6] Ulsoy, A. G.; Mote, C. D., Jr. Vibration of Wide BandSaw Blades. // ASME Journal of Engineering for Industry. 104, (1982), pp. 71-78. DOI: 10.1115/1.3185801

[7] Lucisano, G.; Stefanovic, M., Fragassa, C. Advanced Design Solutions for High-Precision Woodworking Machines. // International Journal of Quality Research. 10, 1(2016), pp. 143-158. DOI: 10.18421/JJQR10.01-07

[8] Fragassa, C. Material selection in machine design: the change of cast iron for improving the high-quality in woodworking. // Proceedings of the Institution of Mechanical Engineers, Part C: Journal of Mechanical Engineering Science. March 2016. DOI: $10.1177 / 0954406216639996$

[9] Mote, C. D., Jr. A studyof band saw vibrations. // Journal of the Franklin Institute. 279, 6(1965), pp. 430-444. DOI: 10.1016/0016-0032(65)90273-5

[10] Wickert, J. A. Non-linear vibration of a travelling tensioned beam. // International Journal of Non-linear Mechanics. 27, 3(1992), pp. 503-517. DOI: 10.1016/0020-7462(92)90016-Z

[11] Öz, H. R.; Pakdemirli, M.; Özkaya, E. Transition Behaviour from String to Beam for Axially Accelerating Material. // Journal for Sound and Vibration. 215, 3(1998), pp. 571576. DOI: $10.1006 /$ jsvi.1998.1572

[12] Özkaya, E.; Pakdemirli, M. Vibrations of an axially accelerating beam with small flexural stiffness. // Journal of Sound and Vibration. 234, 3(2000), pp. 521-535. DOI: 10.1006/jsvi.2000.2890

[13] Huang, J. L.; Su, R. K. L.; Li, W. H.; Chen, S. H. Stability of an axially moving beam tuned to three-to-one internal resonance. // Journal of Sound and Vibration. 330, (2011), pp. 471-485. DOI: 10.1016/j.jsv.2010.04.037

[14] Tang, Y-Q.; Chen, L-Q.; Yang, X-D. Nonlinear vibrations of axially moving Timoshenko beams under weak and 
strong external excitations, // Journal of Sound and Vibration. 320, (2009), pp. 1078-1099. DOI: 10.1016/j.jsv.2008.08.02

[15] Ding, H.; Zu, J. W. Periodic and chaotic responses of an axially accelerating viscoelastic beam under two-frequency excitations. // International Journal of Applied Mechanics. 5, 2(2013), pp. 1-39. DOI: 10.1142/S1758825113500191

[16] Yan, Q-Y.; Ding, H.; Chen, L-Q. Periodic responses and chaotic behaviours of an axially accelerating viscoelastic Timoshenko beam. // Nonlinear Dynamics. 78, (2014), pp. 1577-1591. DOI: 10.1007/s11071-014-1535-6

[17] Tang,Y-Q.; Chen, L-Q.; Yang, X-D. Natural frequencies, modes and critical speeds of axially moving Timoshenko beams with different boundary conditions. // International Journal of Mechanical Sciences. 50, (2008), pp. 1448-1458. DOI: 10.1016/j.jjmecsci.2008.09.001

[18] Ding, H.; Zhang, G. C.; Chen, L. Q. Supercritical equilibrium solutions of axially moving beams with hybrid boundary conditions, Mechanical Research Communications. 38, (2011), pp. 52-56. DOl: 10.1016/j.mechrescom.2010.12.003

[19] Chen, L-Q.; Yang, X-D. Nonlinear free transverse vibration of an axially moving beam: Comparison of two models. // Journal of Sound and Vibration. 299, (2007), pp. 348-354. DOI: 10.1016/j.jsv.2006.06.045

[20] Ghayesh, M. H.; Balard, S. Non-linear parametric vibration and stability analysis for two dynamic models of axially moving Timoshenko beams. // Applied Mathematical Modelling. 34, (2010), pp. 2050-2059. DOI: 10.1016/j.apm.2009.12.019

[21] Tang, Y-Q.; Chen, L-Q.; Yang, X-D. Parametric resonance of axially moving Timoshenko beams with time dependent speed. // Nonlinear Dynamics. 58, (2009), pp. 715-724. DOI: 10.1007/s11071-009-9512-1

[22] Öz, H. R.; Pakdemirli, M. Vibrations of an Axially Moving Beam with Time-Dependent Velocity. // Journal of Sound and Vibration. 227, 2(1999), pp. 239-257. DOl: 10.1006/jsvi.1999.2247

[23] Chen, L. Q.; Yang, X. D. Parametric resonance of an axially accelerating viscoelastic beam with non-typical boundary conditions. // Proceedings of IUTAM Symposium on Dynamics and Control of Nonlinear Systems with Uncertainty, Nanjing, China, September 18-22, 2006, pp. 217-226. DOI: 10.1007/978-1-4020-6332-9_22

[24] Žigulić, R.; Fragassa, C.; Skoblar, A. A nonlinear model of the woodworking bandsaw. // Proceedings of $8^{\text {th }}$ International Congress of Croatian Society of Mechanics, $29^{\text {th }}$ September $-2^{\text {nd }}$ October 2015, Opatija, Croatia, pp. 112.
[25] Savoia, M.; Stefanovic, M.; Fragassa, C. Merging Technical Competences and Human Resources with the Aim at Contributing to Transform the Adriatic Area in a Stable Hub for a Sustainable Technological Development. // International Journal of Quality Research. 10, 1(2016), pp. 1-12.

[26] Wood Bandsaw Stell. URL:http://www.uddeholm.co.uk/ english/files/Wood_Bandsaw_Steel.pdf. (31.1.2016)

\section{Authors' addresses}

Roberto Žigulić, Professor

Department of Mechanical Engineering,

Faculty of Engineering Rijeka, University of Rijeka Vukovarska 58, 51000 Rijeka, Croatia

E-mail: zigulic@riteh.hr

Cristiano Fragassa, PhD

Department of Industrial Engineering, University of Bologna,

Viale Risorgimento 2, 40136 Bologna, Italy E-mail: cristiano.fragassa@unibo.it

Ante Skoblar, PhD

Department of Mechanical Engineering, Faculty of Engineering Rijeka, University of Rijeka Vukovarska 58, 51000 Rijeka, Croatia

E-mail: askoblar@riteh.hr 